\title{
A network-design analysis of airline business model adaptation in the face of competition and consolidation
}

\author{
Renan P. de Oliveira ${ }^{a, b}$ \\ Alessandro V. M. Oliveira ${ }^{\mathrm{a},+}$ \\ Gui Lohmann ${ }^{b}$
}

\begin{abstract}
By focusing on the intrinsic relationship between business models and network configurations in the airline industry, this paper develops a two-stage methodology to estimate the strategic drivers of network design of the major carriers in Brazil. The empirical approach decomposes their domestic network-building rationales into the ones adopted by virtual archetypical carriers. We consider the previously conceived low-cost, full-service, and regional carrier archetypes. Our main contribution is the development of a model that allows airlines' networks to be strategically designed in a timeevolving pattern, reflecting a dynamically chosen blend of these archetypes. Moreover, we also consider the effects that mergers and acquisitions may have had in inducing changes in these blends. Our results suggest that all analyzed airlines have repositioned themselves through their trajectories to adopt a hybrid configuration, aiming at the intersection of at least two archetypical networkdesign rationales. Besides, the effects of consolidations point to certain diversions of the acquiring airlines' domestic network-building rationales towards the ones of the acquired carriers, providing evidence that the consolidations may have served as stepping stones for market-repositioning moves.
\end{abstract} Keywords: airline; business model convergence; econometrics; merger; product differentiation.

JEL Classification: D22; L11; L93.

\footnotetext{
${ }^{a}$ Aeronautics Institute of Technology, Brazil.

${ }^{\mathrm{b}}$ Griffith University, Australia.

${ }^{+}$Corresponding author. Email address: alessandro@ita.br.

- Acknowledgments: the second author wishes to thank the São Paulo Research Foundation (FAPESP) - grants n. 2013/14914-4 and 2015/19444-1; the National Council for Scientific and Technological Development (CNPq) - grants n. 301654/2013-1, n. 301344/2017-5 and PIBIC; and Coordination for the Improvement of Higher Education Personnel (CAPES) - Finance Code 001. The authors wish to thank Cristian Vieira dos Reis, Luiz André Gordo, Vitor Caixeta Santos, Paula Guimaraes, Rodolfo Narcizo, Cláudio Jorge P. Alves, and Rogéria Arantes. All remaining errors are ours.
} 


\section{Introduction}

Attracted to travel due to affordable airfares, new price-sensitive customers fueled the expanding adoption of the low-cost carrier (LCC) business model upon its debut worldwide. While sticking to secondary airports and maintaining point-to-point operations were key strategies in the rapid growth of companies following this model, it did not take long for LCC markets to increasingly overlap with those of full-service carriers (FSCs) (Franke, 2004; Morrell, 2005; de Wit \& Zuidberg, 2012). Beginning with short-haul routes where FSCs were virtually priced out, LCCs soon began to appeal to business travelers, whose choices were increasingly price-driven and who were otherwise indifferent to choosing between LCCs and FSCs (Mason, 2001). ${ }^{1}$ In Europe, those passengers accounted for as much as one fifth of Ryanair's customers in $2013 .{ }^{2}$ Norwegian Air Shuttle's ${ }^{3}$ and Southwest's ${ }^{4}$ long-haul flights further attested to the role of business travel demand in the evolution of LCCs. However, the deep linkage between business models and network structures meant that increased complexity in their operations would follow from that new state of affairs. ${ }^{5}$

On the other side of the tug of war, FSCs readily reacted to the LCC model. LCC subsidiaries, an early attempt by FSCs to deter rival LCCs' forays with competitive 'fighting brands,' nevertheless, have been mostly unsuccessful (Whyte \& Lohmann, 2015). Incompatibilities in the FSC and LCC business models (leading to conflicting strategies), significant differences in cost, brand confusion and cannibalization of markets have been cited as causes for their demise (Graf, 2005; Gillen \& Gados, 2008). Indeed, isolated examples of successes of such strategies are said to have been owed primarily to the separated operations between the subsidiary and the parent carrier (Lindstädt \& Fauser, 2004; Morrell, 2005; Whyte \& Lohmann, 2015). These and other experiments, carried out precisely by the companies with least financial leeway — coupled with the financial volatility that is peculiar of the air transportation industry-eventually contributed to a rushed overhaul of the traditional FSC model. Particularly since the 2000s, FSCs have begun to adopt a set of traits from their LCC rivals ${ }^{6}$ with hopes of obtaining greater flexibility in their operations - mostly translated as cost-cutting, service unbundling and network restructuring initiatives. Adaptation to everchanging market circumstances and customer needs resulted in both opposing sides converging with one another, with a somewhat 'hybrid' business model starting to insinuate itself halfway, as an integrated strategy of competition through both cost leadership and product differentiation (Lohmann \& Koo, 2013).

Furthermore, over time, the inevitable thickening of many regional routes and the rising average size of regional aircraft - easily deployed on mainline routes for increased frequencies of service by carriers associated with any of these business models-have opened up the opportunity for the 
operation of markets previously unprofitable for both FSCs and LCCs (Holloway, 2008). In this way, yet another dimension has been brought to the business model convergence issue, namely, that of the regional carrier business model (hereafter RGC). Increasingly blurred boundaries amongst the use of attributes of these various models have led to a process of hybridization, where airlines have enhanced their competitive advantages by adjusting their operations to better cater to individual markets.

In this context, by considering how typical airlines' business models create the conditions and constraints for setting up their network structures and, observing the actions of a set of companies during particular periods of their trajectories, reflecting a given ideal airline archetype networkdesign rationale — FSC, LCC or RGC — we aim to analyze airline business model convergence from the perspective of an empirical network-design analysis. We, therefore, raise the following research question: "Given a set of archetypical business models and their corresponding network-design determinants and constraints, how do carriers' observed domestic network behaviors conform with these archetypes?".

In this study, both route and airport characteristics commonly associated with these archetypical models are considered, with domestic Brazilian air transportation data corresponding to the period between January 2001 and December 2018 being employed. This particular setting is chosen given the remarkable expansions and subsequent business model adaptations of two LCCs, i.e., Gol and Azul. In addition, a series of mergers and acquisitions (henceforth jointly referred to as consolidations) involving diverse combinations of business models (LCC-FSC, FSC-FSC, and LCC-RGC) also took place.

The main contribution of this study lies in the development of an econometric framework to examine how network-design patterns of existing carriers conform to traditional archetype network rationales, while also providing a means of evaluating the extent to which convergence or divergence has taken place among these carriers. This setup, furthermore, allows us to make an inference as towards which archetype (FSC, LCC, or RGC) convergence (if any) has occurred. We also contribute to the literature by utilizing an existing estimation method in a previously unexplored setting. So far, very few academic papers have employed a multivariate probit framework to inspect phenomena related to the airline industry and, to the best of our knowledge, all of them were related to passenger behavior (e.g., Blackstone et al., 2006; Barros, 2012; Milioti et al., 2015). Our paper is the first in the literature to consider the multivariate probit framework in an airline decision-making context. 
Moreover, when considering the effects of consolidations, we further investigate the role that acquired firms may have played in providing the necessary conditions for implementation and/or adaptation of network-design rationales - a way for airlines to better position themselves in the market. In this manner, they might have either allowed a reorientation already longed for, but previously unsuccessful—given the constraints imposed by their business models—or offered the company an off-course market opportunity worth pursuing.

The remainder of this paper is organized as follows. A review of the existing literature regarding airline business model convergence, including the effects of consolidation, is presented in Section 2. Section 3 then provides an overview of the carriers in our sample, along with an analysis of their operational data. Section 4 specifies the research design, the data set, and the development of our empirical model. Estimation results are evaluated and discussed in Section 5, which are followed by the conclusions in Section 6.

\section{Conceptual framework}

\subsection{Business model convergence}

In the process of classifying a company as being associated with a given business model archetype, a set of traits is usually assessed. In the case of LCCs, these traits traditionally have rested upon those of Southwest's business model in the early 1990s, with features such as short-haul flights, point-to-point route design, secondary airport-based operations, high aircraft utilization, fleet commonality, high labor productivity, single service class, unbundled fares, limited air cargo and no alliance memberships, to name a few (Holloway, 2008). These features provided a departure from those commonly associated with the FSC model, locked into practices having the highest contrast with the LCC model, given their targeted customer base (i.e., mostly business travelers). Holloway (2008) offers a discussion on how service expectations by these carrier's primary customers have hindered their adaptation to these and other LCC features.

In practice, however, most companies do not rigidly follow such textbook templates. One could argue that, as airlines' products become more standardized, the most cost-efficient companies may attain the goal of consolidating their LCC image more easily in the market, thus becoming the 'goto' company in this niche and forcing their competitors to deviate in one way or another from the traditional model, differentiating themselves in order to survive. Mason \& Morrison (2008) provide evidence for this assertion. However, using a product and organizational architecture (POA) approach to the business models of six European LCCs, these authors suggest that deviations from 
the pure LCC traits - to which Ryanair has conformed the most - proved to be a less profitable strategy for those firms.

Daft \& Albers (2013) examine the classification of airlines by a set of indices. By proposing a framework for studying the business model convergence of five German airlines, their results point to convergence towards the FSC model. Similar results can also be found in a more comprehensive study by the same authors (Daft \& Albers, 2015), where they additionally report that, in comparison with FSCs, LCCs tend to have higher levels of differentiation among themselves, usually as a consequence of the aggressive expansion efforts that LCCs make to attract business passengers.

Following this literature, Lohmann \& Koo (2013) propose the 'airline business model spectrum,' further examined by Jean \& Lohmann (2016). Using data from major U.S. carriers in the period from 2011 to 2013, Jean \& Lohmann (2016) found evidence of a propensity for merged airlines to move towards the FSC end of the spectrum, deviating significantly from their original business models in the face of such events, while individual airlines not involved in a merger moved towards the LCC side.

In addition, Klophaus et al. (2012), while investigating changes in European LCCs' business models towards hybrid strategies, found that many airlines deviating from the pure LCC model did so mainly regarding their 'airport choice' and 'network strategy' traits. Lange \& Bier (2019) and Roucolle et al. (2020), by employing a set of metrics from graph theory followed by a principal component analysis (PCA), provided further evidence of the central role of network structures in defining airlines' business models and in understanding their evolution. Lange \& Bier (2019) found that European airlines with related models shared significant similarities, mainly associated with the coverage of their networks and frequencies of service. Conversely, Roucolle et al. (2020) suggested a distinction between American LCCs' and FSCs' domestic network structures in terms of their ability to mitigate disturbances through alternative routings. However, Roucolle et al. (2020) did not find the same contrast in terms of the presence of central nodes in these carriers' networks, noted by them as being consistent with recent analyses on the convergence of airline business models. As such, these results seem to justify and pave the way for more econometric-oriented treatments of the business model convergence issue from a network perspective, based primarily on available supply and demand data. An example of such an investigation is offered by Fageda et al. (2015), who examined the market entries into the European air transportation industry throughout the summer of 2013. The authors found that different sets of route characteristics are taken into account by archetypical LCCs and hybrid airlines when configuring their networks, with a widening gap between their operations being primarily manifested in the 'fare unbundling' and 'point-to-point operations' tenets of the pure 
LCC model. By focusing only on a brief period, Fageda et al.'s research was not concerned with possible ongoing changes in business models. In a similar econometric vein, although encompassing a broader interval of time, Henrickson \& Wilson (2016) examined airport and route choice decisions made by legacy carriers and LCCs within the U.S. airline industry. Using a difference-in-differences approach, they found evidence of convergence of these airlines' strategies over the 21 years from 1993 to 2013, specifically towards the FSC model.

These results reinforce the notion that convergence is taking place in the air transportation industry within both the U.S. and Europe, mostly manifested by LCCs moving towards the FSC model, although with varying strategies - be it by network developments, higher flight frequencies, loyalty programs or in-flight amenities (Mason \& Morrison, 2008; Daft \& Albers, 2013; Lohmann \& Koo, 2013; Jean \& Lohmann, 2016; Klophaus et al., 2012; Fageda et al., 2015; Henrickson \& Wilson, 2016).

Based on the findings of the previous literature, we, therefore, have evidence that a carrier's business model, and its route network, may gradually drift away from the archetypical baseline followed by it in its past strategies. At any given moment when revising its long-run strategies, a carrier has to decide to either remain faithful to its original archetype and network-design practices - or archetypes, if the carrier already maintains a 'mixture' of them — or to make some key adjustments. Given this potential strategic 'tune-up,' we conjecture the following:

Hypothesis $\mathbf{H}_{1}$ : At any given time, airlines' networks are decomposed into a blend of archetypical ones.

With Hypothesis $\mathbf{H}_{1}$, we aim to trace back how each company's network looked throughout the timeline of our dataset.

We further highlight that in this research we consider the regional carrier archetype (RGC), often overlooked in previous research in this field. We contend that carriers associated with this model present sufficiently distinctive features - indeed, to the point of forming a separate sector of the industry - being worthy of a category of their own. Features of such archetype include the use of smaller aircraft than the ones operated by FSCs or LCCs (often regional jets or turboprop aircraft with less than 120 seats); a focus on servicing thinner routes, mostly having shorter stage lengths than those of the other archetypes; specialization on particular geographical or market niches and preference for secondary and tertiary airports (Doganis, 2006; Holloway, 2008; Bilotkach \& Pai, 2014). Given their fleet and cost-structure advantages in the short-haul markets, these carriers have often engaged in the provision of feeder traffic to major FSCs, linking regional airports to major 
hubs. In many cases, these carriers have been established as subsidiaries of these FSCs, alternatively being operated independently or as franchisees with inter-line agreements. We note, however, that in the particular case of regional subsidiaries of major carriers, these are treated in this research as part of the airline group to which they belong.

Lastly, given the results of Jean \& Lohmann (2016) and Roucolle et al. (2020), we also consider the possible disruptive effects that consolidations may have had on the ongoing evolution of carriers' networks. This concern is relevant given how organizational and structural changes are a frequent companion to consolidations and, understandably, may induce substantial business model diversions. These diversions may occur naturally (passively), or they may have been previously intended by a given airline as a market repositioning strategy. With this, the company may have been aiming at a new set of markets in which to operate. However, given the role of a company's network in the setting of its brand identity and the definition of its business model (Holloway, 2008), the consolidation may have produced a much more significant reorientation effect than expected. As such, we test the following hypothesis:

Hypothesis H2: From the perspective of an airline's network, consolidation events have a disruptive effect on their business models, be it by facilitating reorientation needs already intended or by offering new market opportunities.

We note, however, that in this research we do not aim to distinguish between the causes for such reorientations, focusing only on the occurrence of any network design diversion resulting from the consolidation events.

\section{Background to the evolution of Brazilian airlines}

Now, turning our attention to the Brazilian air transportation industry, a summary of its major carriers, their evolvement and relevant events is presented. By the end of the period under analysis (December 2018), the leading airlines, LATAM Airlines Brazil, Gol Intelligent Airlines, Azul Brazilian Airlines and Avianca Brazil, controlled the market - a clear contrast to the situation in the mid-2000s, when 'old-timers' Gol and (then) TAM used to dominate alone. ${ }^{7}$ This situation is depicted in Figure 1, presenting the market share evolution in terms of revenue passengers at the national level of the four carriers from January 2001 to December 2018. TAM and Gol reached their peak by August 2006, with $87.73 \%$ of the market. 


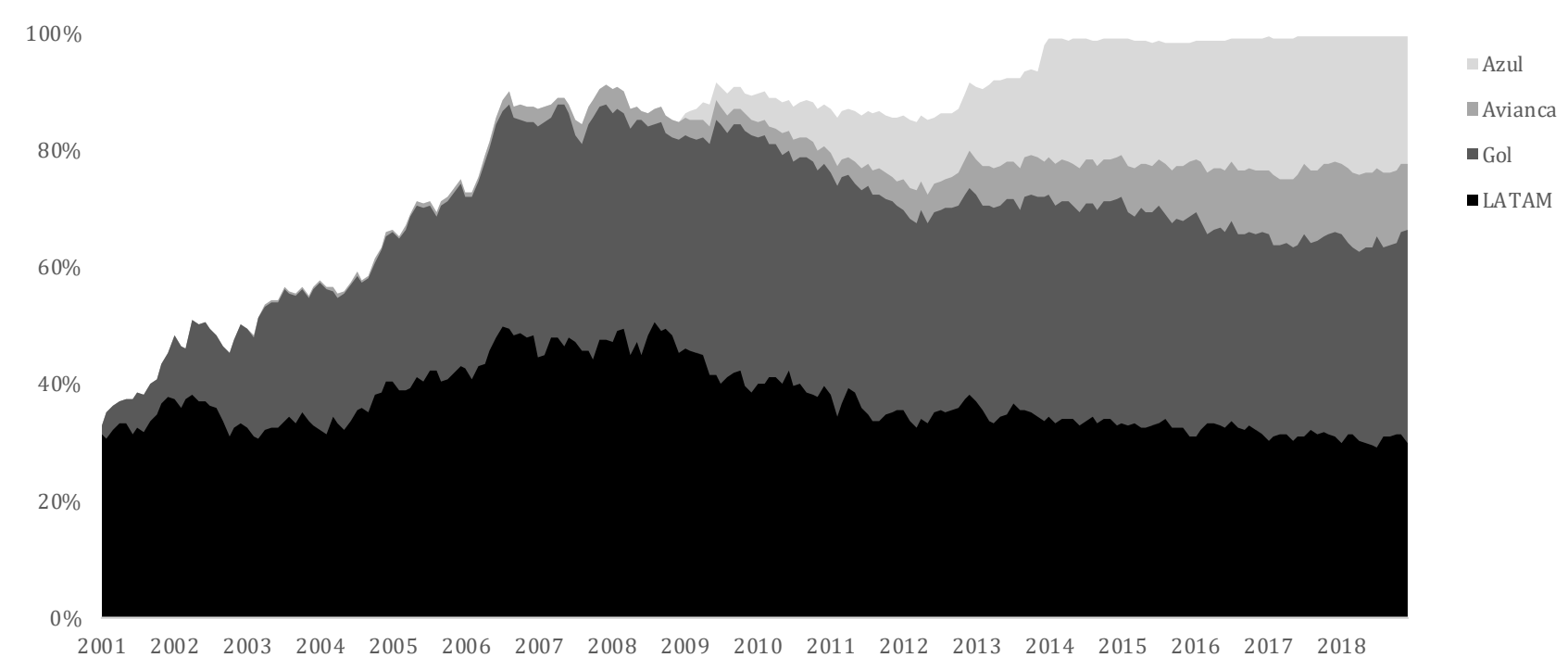

Figure 1 - Domestic shares of revenue passengers of the analyzed companies at the national level

Source: National Civil Aviation Agency (Agência Nacional de Aviação Civil-ANAC), with own calculations, 2001-2018.

TAM, stimulated by the liberalization of the Brazilian air markets in 1998, went from a small regional carrier to the country's biggest full-service carrier (FSC) - in the process replacing old Fokker F-50 and F-100 planes with a modern Airbus A320 family fleet. In 2010, TAM's merger with Chilean legacy carrier LAN gave rise to Latin America's largest airline, LATAM. However, this merger did not significantly affect its ongoing business model orientation.

Gol, Brazil's first low-cost carrier (LCC), made its debut in 2001, rapidly growing to become a key player in the country. The acquisition of bankrupt legacy carrier Varig in 2007, however, would significantly reorient Gol's business strategies, as a consequence of the integration of its operations with the once most important flag carrier and largest network airline in Brazil. As recently as 2017, the company has strived to reestablish its business model as an LCC, marketing itself ${ }^{8}$ as one of "the five largest low-cost carriers globally" with the "the only true low-cost carrier business model in Brazil."

Nevertheless, the duopoly of Gol and TAM did not last long, as it was soon contested by 'newcomers' Azul and Avianca. Azul began operations in December 2008, entrenching itself at the São Paulo/Campinas secondary airport. From there, equipped with a fleet of Embraer E190/E195 aircraft, the company rapidly gained ground as Brazil's leading LCC, a label later challenged by its acquisition of regional carrier Trip Airlines, in 2012. In general terms, Azul's network expansion proved to be highly successful, as attested by its leading position in terms of the number of departures and cities served in the country, as of December $31,2018 .^{9}$ 
In 2010, Avianca Brazil was established. As the outcome of a major rebranding and business model revamp of OceanAir (founded in 2003 as a small regional carrier), the company has since successfully repositioned itself in the market, with a distinct FSC flair, following the replacement of its Fokker-100 aircraft with Airbus A318s and A319s. A subsidiary of the Synergy Group, the parent company of Avianca Holdings (to which Avianca Colombia among other airlines in Latin America belong), Avianca's operations in Brazil have notably been kept independent from the rest of the group since its launch. Its fast capacity growth-or more specifically, its over-investments in capacity, themselves not followed by an increase in demand-a key ingredient for securing the airline a place in Star Alliance as early as July 2015, is considered one of the causes of its filing for bankruptcy in December 2018.

Table 1 presents a set of characteristics of these carriers related to the Brazilian air transportation industry in 2017. We note that the newcomers Azul and Avianca reached medium-sized operations in a short timeframe, with RPK market shares of $17.8 \%$ and $12.9 \%$ respectively. Aiming at the (then) unattended niche of 'high-quality travel experience,' their offering of features such as free in-flight entertainment and greater seat pitch proved to be popular. ${ }^{10}$ Furthermore, in Table 1 we can see that Azul, despite its orientation towards high standards of service, has consistently shown the lowest trip costs, proving to be a match for Gol when it comes to low-cost operations (which, in its turn, holds the lowest cost per available seat-kilometer-CASK).

Data from Table 1 suggest that findings of the previous literature (e.g., Daft \& Albers, 2013, Lohmann \& Koo, 2013) may also apply to the Brazilian experience. As noticed, TAM evolved from a regional carrier to a top-tier FSC with the establishment of LATAM, with Avianca Brazil following the same expansion pattern, from regional to mainline FSC operations-although without full integration with a major Latin American airline holding. Gol, alternatively, started as a pure LCC, having since shown some difficulty in repositioning itself again as such after the acquisition of legacy carrier Varig - not to mention its ambition in gaining a larger market share from the business travelers' segment. Lastly, Azul, although having vigorously promoted its main hub in Campinas, positioning itself as an industry maverick with low fares and a seemingly LCC behavior in its early years, became, eventually, the carrier with the highest average yield — roughly 11.2 cents USD, 60\% higher than Gol's - and with the most significant stake in the monopoly markets of the industry's regional segment (in the wake of Trip's acquisition). 
Table 1 - Characteristics of the major Brazilian airlines in 2017

Business model key elements (self-description)

\author{
"the largest passenger and \\ cargo airline in South \\ America"; "significant \\ presence in the largest hubs" \\ "(we) offer the best \\ connectivity options"; "We \\ are continually working to \\ maintain a competitive cost \\ structure"
}

"a

\section{Revenues}

Total revenue (billion USD)

Revenue - Domestic (\%)

Revenue - International (\%)

Revenue - Charter (\%)

Costs

Total Operating Costs (billion USD)

Costs - Labor (\%)

Costs - Fuel (\%)

Costs - Capital-related (\%)

Costs - Fees (\%)

Costs - Other (\%)

Commercial Expenses per pax (USD)

Trip Cost (thousand USD)

CASK (cents USD)

\section{Profitability}

Total Operating Profits (billion USD)

Gross Margin (\%)

4.7
$59.0 \%$
$41.0 \%$
$0.0 \%$

3.8
$23.9 \%$
$28.9 \%$
$25.4 \%$
$9.0 \%$
$12.7 \%$
10.6
17.0
5.6

0.9
$18.2 \%$

2.8
$84.2 \%$
$1.4 \%$
$6.6 \%$
$7.9 \%$
7.8
$32.6 \%$
$83 \%$
173
9
11.5
984
$16 \%$
15
43

GRU, CGH, BSB, GIG

3.2
$83.8 \%$
$15.1 \%$
$1.1 \%$


2.3
$18.8 \%$
$39.3 \%$
$24.6 \%$
$9.8 \%$
$7.5 \%$
8.6
9.2
4.9


0.9
$27.0 \%$

Domestic Market Positioning

Total revenue - Scheduled (billion USD)

Revenue - Tickets (\%)

Revenue - Baggage (\%)

Revenue - Cargo \& Mail (\%)

Revenue - Auxiliary Revenues (\%)

Average Yield (cents USD)

Market share (RPK)

Average Load Factor (\%)

Average Aircraft Size (seats)

Average Aircraft Age (years)

Aircraft flight hours per day

Average Stage Length $(\mathrm{km})$

Delayed Flights (\%)

Number of Complaints (per 100,000 pax)

Number of Served Cities (count)

Hubs \& Focus Cities

Fleet size (count)

Fleet Standadization Index (HHI - model)

Fleet composition

"a low-cost carrier focused
on offering low fares with
high-quality customer
experience"; "'the lowest
operating cost (CASK)"

"the largest network in Brazil"; "(we) connect more passengers than our competitors"; "high-quality, differentiated travel experience"; "low-cost operating

model"; "trip cost advantage relative to our main competitors" "high product-quality"; "service differentials to customers, such as individual free in-flight entertainment, meals and greater space between seats"

$\begin{array}{cc}2.5 & 1.2 \\ 84.3 \% & 96.2 \% \\ 15.7 \% & 3.8 \% \\ 0.0 \% & 0.0 \% \\ & \\ 1.9 & \\ 20.7 \% & 0.9 \\ 30.3 \% & 25.2 \% \\ 33.8 \% & 36.5 \% \\ 8.0 \% & 22.6 \% \\ 7.2 \% & 7.1 \% \\ 4.6 & 8.5 \% \\ 7.5 & 7.9 \\ 7.5 & 10.8 \\ & 6.2 \\ 0.6 & \\ 24.8 \% & \\ & 0.2 \\ 2.1 & 19.3 \% \\ 85.9 \% & \\ 1.3 \% & 1.1 \\ 2.7 \% & 83.3 \% \\ 10.1 \% & 1.0 \% \\ 11.2 & 4.3 \% \\ 17.8 \% & 11.4 \% \\ 80 \% & 7.9 \\ 109 & 12.9 \% \\ 5 & 85 \% \\ 10.1 & 151 \\ 700 & 5 \\ 12 \% & 11.3 \\ 12 & 1,036 \\ 101 & 18 \% \\ & 13 \\ & 25 \\ & \\ & \\ & \\ & \end{array}$

VCP, CFN, REC

GRU, BSB, SSV
0.395
109

106

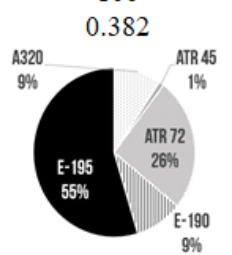

41 0.668

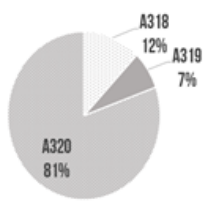

Sources: Statistics from the National Civil Aviation Agency (ANAC) found on the Air Transport Yearbook, the Air Transport Demand and Supply Report - Brazilian Companies, the Air Transport Statistical Database, the Flight History - Active Regular Flight (VRA), the Brazilian Aeronautical Registration (RAB), the Integrated Civil Aviation Information System (SINTAC), United States Securities and Exchange Commission Form 20-F (Gol, LATAM, Azul), and Avianca's website, at the "Who We Are" section, accessed in 12/20/2018 (www.avianca.com.br/en/quem-somos), with own calculations. 
Overall, we have evidence that in the period from 2001 to 2018, all four carriers in Brazil have intensively adjusted their market behavior in a strategic tune-up of their business models. Market characteristics and competition seem to be the dominant forces of latent market profitability that gave momentum to these changes. With that in mind, our primary research purpose is, therefore, to identify, isolate and compare the key factors underlying these adjustments to these carriers' route network planning and network design which took place during that time.

Drawing from the literature definitions of business model features, detailed in Section 2, and focusing on those features related to network design, we pay particular attention to market characteristics such as distance (as LCCs and RGCs in principle show a preference for short-haul markets - in the case of the former given their goals of high aircraft utilization and point-to-point operations and in the case of the latter given their use of smaller aircraft); the presence of central airports in the carriers networks as well as the avoidance of concentrated/dominated airports (to control for an inclination for secondary/tertiary airport-based operations); and, finally, figures of air traffic and average income of the endpoint cities of the routes (to control for preferences for serving either thinner or denser routes, as the purchasing power of passengers will have an essential role in the case of the former).

\section{Empirical models of network design}

To implement our econometric models of network design, we used data from the National Civil Aviation Agency (ANAC) and the Brazilian Institute of Geography and Statistics (Instituto Brasileiro de Geografia e Estatística-IBGE). We employed longitudinal data (panel data) with monthly observations of routes in the Brazilian domestic market comprising a sample period between January 2001 and December 2018, associated with the operation of carriers Gol, Azul, Avianca Brazil (formerly known as OceanAir) and LATAM (formerly TAM). These were chosen to examine all archetypes associated with the regular transportation of passengers, namely, the fullservice carrier (FSC), the low-cost carrier (LCC) and the regional carrier (RGC). These are to be contrasted with other airline business models identified in the literature that do not satisfy such requirements (e.g., air cargo carriers, charter carriers, and business executive carriers). See the Appendix for details on the utilized data set.

We built all archetypical network-design rationales using data from January 2001 to December 2005, the first five years of a genuine free market in the Brazilian air transportation industry following deregulation, a period in which all carriers started to learn how to position themselves in the market. This timeframe provided valuable experiences for all Brazilian carriers, and hence, was critical to 
the fine-tuning of their identities. We note that our definitions of carriers as depictive archetypes are primarily based on accounts from the general and the specialized media, how these carriers defined themselves (e.g., on reports to investors), as well as on previous research considering this period. In this way, we chose TAM Airlines' operations to represent our 'full-service carrier (FSC) archetype,' the Brazilian airline that conformed the most to the classical FSC business model during that time. TAM has been previously defined as an FSC in studies such as those by Huse \& Evangelho (2007) and Varella et al. (2017). Furthermore, OceanAir's early network developments underpinned our 'regional carrier (RGC) archetype,' a period during which the company's fleet consisted mainly of aircraft with seat capacity within the 50-110 seat range. This was devised as a way to capture some characteristics commonly associated with this archetype, such as the operation of thin markets with small distances, confined mainly to a particular portion of the country's territory. Finally, for the 'low-cost carrier (LCC) archetype,' we considered Gol's behavior during its startup period. This accounts for both strategies associated with its first months of operations, when it was heavily influenced by Southwest's classical LCC model — mostly marked by a predominantly point-to-point network - and strategies pursued during the following years, expanding its operations to longer routes and, to some degree, incorporating hub-and-spoke network features. Gol has been previously defined as an LCC in studies such as those by Evangelho et al. (2005), Oliveira (2008), and Koo \& Lohmann (2013).

Our proposed methodology comprises two sequential stages, representing (1) the construction of idealized archetypical carriers whose network-design rationales are extrapolated to the whole Brazilian air transportation market, based on the behaviors of a set of airlines during key periods of their trajectories; and (2) the decomposition of Brazilian airlines' actually adopted network-design behaviors into mixtures of these previously constructed archetypes, all that while also accounting for possible influences of consolidation events and the time evolution of these carriers' archetype decompositions. We summarize the proposed two-stage methodology for network-design rationale identification in Figure 2. 


\section{$\underline{1^{\text {st }} \text { Stage: Archetypical network design rationales }}$}

Define depictive carriers/periods (business model archetypes)

Run individual route selection probit (logit) models using data from each one

Generate probit (logit) predictions to extrapolate the found network-design rationales to the whole sample of routes and periods (creating, thus, virtual archetypical carriers)

Use of these virtual archetypical carriers as the regressors in the $2^{\text {nd }}$ stage models

\section{$\underline{2^{\text {nd }}}$ Stage: Existing carriers' network design drivers}

Run a route selection multivariate probit model jointly for all carriers, isolating influences of their archetypical blends, their evolution and consolidation events

Figure 2 - Stages of the proposed methodology

\subsection{Stage 1 - Construction of archetypical rationales}

We employ the probit model as our main specification for the decision of archetypes to operate markets, following the modeling undertaken by, e.g., Berry (1992), Boguslaski et al. (2004) and Oliveira (2008). Furthermore, to test for the impacts of the selection of a different first-stage model on the subsequent regression analysis, we also made use of the logit model, with the works of Dresner et al. (2002) and Gil-Moltó \& Piga (2008) serving as examples of its applications in similar settings. In the probit framework, we set $p_{a}$ to account for the presence of archetype $a \in A=$ $\{F S C, L C C, R C G\}$ on route $i$ and at period $t$. Each archetype is regressed separately with its presence on a given route being designated by the value '1.'

The literature on airline decision-making concerning network design typically considers a set of route, airport, and demographic features that are possibly related to the attractiveness of entering a market (e.g., Boguslaski et al., 2004; Oliveira, 2008; Müller et al., 2012). These features include characteristics such as market density and distance; endpoint cities' characteristics such as population and income; proxies for network size, such as the number of destination cities served from each of the endpoint cities or the presence of a hub of the analyzed carrier on either of the endpoint cities; and also metrics of competition and dominance such as the market/airport/city level Herfindahl-Hirschman Index (HHI) of market concentration. We draw from the literature above and utilize the following variables in the specification of the empirical models of this stage: DIST, the Vincenty distance between the endpoints of a route; DIST ${ }^{2}$, the square of DIST; INCOME, the 
maximal GDP per capita between origin and destination cities of a route; NETWORK, the maximal number of cities served to/from the origin and destination cities of a route, $P A X$, the average number of monthly revenue passengers on the route, and HHI, the Herfindahl-Hirschman index (HHI) of concentration of revenue passengers on the route. Both PAX and HHI are treated as endogenous regressors. We also include dummy variables to account for origin/destination regions and monthly seasonality, and also a time trend, to control for spatial- and time-varying unobserved effects. Details of each variable are found in the Appendix.

To account for the interdependence between different routes and between a route and itself in different periods, we further consider, respectively, spatial and temporal correlations among the observations, using probit and logit models with two-dimension-clustered standard errors-the interested reader is referred to Cameron et al. (2006), Guan \& Petersen (2008), Thompson (2011) and Cameron et al. (2011) for more details. The employed estimated standard errors clusters are city-of-origin/time and city-of-destination/time. In this way, we can account for within-airline strategy consistency, allowing for the clustering of routes that depart from or arrive at the same airport, and thus account for the interdependence between similar routes (i.e., city-pair markets) from/to the origin and destination cities at the same period. Besides, we also capture a sort of 'incumbency power,' due to inertial profitability of the firm maintaining its operations on a route already belonging to its network.

We account for the endogeneity of the $P A X$ and $H H I$ variables in our empirical framework in the following way. Our instrumentation strategy is based on an adaptation of the approach of Borenstein \& Rose (1994) and Gerardi \& Shapiro (2009) for airline price dispersion. Borenstein \& Rose (1994) utilize, among others, an adjusted metric of market concentration in which each carrier's market share is extracted from the overall HHI calculation and replaced by its fitted values obtained from a first-stage regression. We avoid running auxiliary regressions of market shares, which in our case is a procedure that may suffer from omitted variable bias. Therefore, we utilize the first component of the authors' instrument but without adjustments — namely, the HHI extracted when considering only the archetype's rivals' shares. Borenstein \& Rose (1994) also utilize the lagged number of passengers on the route. Based on that procedure, we use lagged versions of the number of passengers, HHI and rivals' HHI on the route. We experiment with up to 12 one-month lags and perform a LASSO (Least Absolute Shrinkage and Selection Operator) procedure to select the best lags for each variable. The use of lagged instrumental variables can also be found in Evans et al. (1993), Busse (2002), Armantier \& Richard (2008), and Ma et al. (2020), among others. The LASSO procedure is the same as described in Belloni et al. (2012). In all specifications, we challenged the proposed approach with 
weak identification tests, which in all cases soundly rejected the null hypothesis of weak identification. ${ }^{11}$

With Stage 1, we address the estimation of archetype-specific latent profit functions for the sample routes on an initial sample period - a 'training' data set for the recognition of patterns of archetypical behaviors. Then, we seek to extrapolate those archetypical network-configuration rationales to the routes contained on a subsequent sample period - a 'testing' data set for assessing the extent of the influence of each archetype on the behavior of the existing carriers. In other words, we perform outof-sample predictions of the probabilities of route presence of each archetype in future periods. We label the prediction variables as 'PrArch_FSC', 'PrArch_LCC' and 'PrArch_RGC', and insert them into the route presence equations of all carriers in Stage 2.

With this procedure, we intend to explain, in Stage 2, each carrier's profit by the profits that each archetypical business model would have had, had it been present in a 'pure form' at that particular route and at that particular time. We ultimately aim at uncovering a carrier's 'type' by how its latent profitability is decomposed into archetypes' predicted profitabilities.

\subsection{Stage 2 - Decomposition of airline network design drivers}

Consider the following general equation for the profit for firm $j$ (designated as $\pi_{j}$ ), which is assessing whether to enter into a given market or not (Berry \& Reiss, 2007):

$$
\pi_{j}=\bar{\pi}\left(D_{-j}, x_{j}, \theta\right)+\epsilon_{j}
$$

where $D_{-j}$ is a vector of dummies indicating whether firm $j^{\prime}$ s rivals have entered the market, $x_{j}$ is a vector of profit shifters, $\theta$ is a vector of parameters to be estimated, and $\epsilon_{j}$ is an unobserved profit shifter. We model the observed profit shifter vector $x_{j}$ as a function of the profits that would have been exploited by the conceived business model archetypes, called vector PrArch (including their time evolutions and interactions with consolidation events). We then have $x_{j}(\operatorname{PrArch})$ as a determinant of firm $j$ 's post-entry profitability:

$$
\pi_{j}=\bar{\pi}\left(D_{-j}, x_{j}(\operatorname{PrArch}), \theta\right)+\epsilon_{j}
$$

Now, suppose, as in Boguslaski et al. (2004), a latent variable that measures post-entry profitability, $Y^{*}$, and an entry threshold $W$. While considering firm $j^{\prime}$ s decision of whether to enter market $i$ at time $t$ or not, the latent quantity $Y_{j i t}^{*}-W_{j i t}$ is unobservable to the researcher, but the firm's realized network design is not. In our context, the actual entry decisions $Y_{j i t}$ are represented by: 


$$
Y_{j i t}=\left\{\begin{array}{lll}
0 & \text { if } Y_{j i t}^{*}-W_{j i t}<0 & \text { (no entry) } \\
1 & \text { if } Y_{j i t}^{*}-W_{j i t} \geq 0 & (\text { entry }) .
\end{array}\right.
$$

where $Y_{j i t}^{*}$ is modeled as:

$$
Y_{j i t}^{*}=D_{-j i t} \beta+\operatorname{PrArch}_{i t} \delta+u_{j i t}
$$

and where $\beta$ and $\delta$ are vectors of parameters to be estimated, and $u_{j i t}$ indicates the (idiosyncratic) sources of latent profitability (or latent profit shifters) of carrier $j$ in market $i$ at time $t$, hypothesized to be located at a given point in the product-differentiation space. The joint modeling of entry choices by existing potential entrants through (possible) correlations between these idiosyncratic sources of profitability is sought to complete the model, directed at controlling for the $D_{-j i t}$ terms. Also, the analysis of the correlations among such unobservables can provide some insight into whether the companies are either converging or diverging on their network-design initiatives beyond what would be suggested by the archetype-decomposition analysis.

To allow for cross-firm systematic correlations of unobserved latent profitability, we employ a multivariate probit model. The literature to which we aim to contribute provides illustrations on the use of this method for modeling profitability decisions made by distinct firms. In the context of the behavior of firms, such model has been previously employed to inspect the determinants of choices regarding innovation strategies (Crowley \& Jordan, 2017), decisions regarding market participation in imports, exports and exerting political influence (Yasar, 2013), among few others. The multivariate probit model is estimated by the simulated maximum likelihood method of Butler \& Moffitt (1982), later implemented by Cappellari \& Jenkins (2006). In our context, the multivariate probit equation system (Greene, 2018) comprises the following relations:

$$
E\left[u_{j} \mid \operatorname{PrArch}\right]=0, \quad \operatorname{Var}\left[u_{j} \mid \operatorname{PrArch}\right]=1, \quad \operatorname{Cov}\left[u_{j}, u_{k} \mid \operatorname{PrArch}\right]=\rho_{j, k}
$$

for all $j, k \in C$, where $C=\{$ Avianca, Azul,Gol, LATAM $\}$ and where we omit the route and time indexes for ease of notation. In the empirical specification, we set $Y_{j}^{*}$ with the following regressors and control variables: PrArch_FSC,PrArch_LCC and PrArch_RGC, the predictions from the first stage for the latent expected profit variables associated with the 'FSC,' 'LCC' and 'RGC' archetypes, respectively; the interactions of these predictions with consolidation event dummies (MERGER), in the cases of Gol's, Azul's and LATAM's models, and a time trend variable (TREND). As an airline's decision-making concerning the configuration of its network is typically not an immediate process, but, on the contrary, demands some time for being implemented, we opted for lagging these 
regressors by three periods (i.e., a quarter). ${ }^{12}$ The interaction variables allow us to infer to which archetype(s) (if any) each Brazilian carrier has moved towards, or to which network-design rationale(s) they remained faithful. This setting will reflect each company's blend and its time evolution, as described in $\mathbf{H}_{1}$, and the effects of possible disruptions associated with the consolidations, as described in $\mathbf{H}_{2}$. The consolidation events observed in the period were Gol's acquisition of Varig in 2007, TAM's merger with LAN in 2010, and Azul's acquisition of Trip in 2012. We also utilize regional and seasonality dummy variables in the specification of the empirical models. Details of all variables are found in the Appendix.

To check the robustness of our results, we utilize not only the multivariate probit but also the univariate probit and logit in both stages. These estimators are employed to address the possible effects of the relationships between the different model stages. In this way, we experiment with varying estimators across the methodological stages to check the sensitivity of the results regarding the specification of a particular model. We then tested the following combinations of models for the first and second stages: probit-probit, probit-logit, logit-probit, logit-logit, and multivariate probit-multivariate probit, and discuss the different estimation results. We also utilize a version of the probit model in which we directly insert dummies of route presence of the rivals of each airline, as dictated by $Y_{j}^{*}$.

\section{Results}

\subsection{Archetypical network-design rationales}

Table 2 presents the estimation results of the archetypical network-design models. Column (5) gives the results of our main empirical model estimation, related to an instrumental variables probit specification with a time trend and control variables related to seasonal and regional effects. All specifications presented make use of two-dimension-clustered standard errors at the city-oforigin/time and city-of-destination/time levels. In this way, our models are flexible enough to consider temporal and spatial correlations among the observations.

While observing the signs of the regressors, common ground between the FSC, the LCC, and the RGC archetypes is easily identified. Beginning with the DIST variable, we find that all archetypes share a propensity — although, with varying degrees — of serving markets associated with higher distances, a result understood in light of these routes having less competition from alternative modes of transportation (e.g., coach or train services, the latter practically unavailable in Brazil for longdistance passenger transport). The nonlinear term $D I S T^{2}$, however, provides a dampening effect on 
longer routes, most prominently manifested in the RGC model, for all specifications. The inclination to serve markets with an associated higher GDP per capita (as measured by the variable INCOME) seems to be preferred by the regional archetype, an observation that we interpret as being a way in which these carriers may find to cope with thinner markets. In contrast, the opposite is found for the LCC archetype, which, in fact, is commonly associated with more price-sensitive passengers.

Concerning the NETWORK variable, the results indicate a positive influence of this variable in the RGC archetype. This variable provides a measure of carriers' inclination to serve routes having a highly central airport on at least one of its endpoints. We note, however, that this only implies that these airports are central to the networks of the said carrier, i.e., not necessarily central to the geographical Brazilian transportation network.

With respect to the endogenous variables, the results from the $P A X$ variable appear to be unanimous across models, with its effects being somewhat smaller on the RGC archetype, in line with ex-ante expectations, as regional carriers usually operate lower density markets. Moreover, the results from the HHI variable are negative and statistically significant for the FSC and LCC archetypes but not significant for RGC. Again, this was consistent with our ex-ante expectations, as regional airlines in Brazil typically prefer entering markets where they could operate as a monopoly.

Concerning the results of the robustness checks reported in Columns (1) to (4), (6) and (7) of Table 2, these indicate that the majority of variables remained statistically significant irrespective of the use of probit or logit specifications or the use of regional, seasonal, or time trend controls. We only note four sources of dissent among models: (1) the variable INCOME in the FSC model, which had some statistically insignificant results for specifications not controlling for regional effects; (2) the variable NETWORK in the LCC model, which has a statistically significant effect in specifications not controlling for regional, seasonality, and time trend effects; (3) the HHI variable in the RGC model, which presented mostly statistically insignificant results, with the major exception being the specification not controlling for regional, seasonality, and time trend effects; and (4) the variable NETWORK in the FSC model, particularly in relation to the specification of Column (7), associated with the multivariate probit. 
Table 2 - Estimation results of the $1^{\text {st }}$ stage (archetypical rationales)

\begin{tabular}{|c|c|c|c|c|c|c|c|c|}
\hline & $\begin{array}{l}(1) \\
\text { IV } \\
\text { Probit }\end{array}$ & $\begin{array}{l}(2) \\
2 \mathrm{DC} \\
\text { Logit }\end{array}$ & $\begin{array}{l}(3) \\
\text { IV } \\
\text { Probit }\end{array}$ & $\begin{array}{l}(4) \\
2 \mathrm{DC} \\
\text { Logit }\end{array}$ & $\begin{array}{l}(5) \\
\text { IV } \\
\text { Probit }\end{array}$ & $\begin{array}{l}(6) \\
2 \mathrm{DC} \\
\text { Logit }\end{array}$ & $\begin{array}{c}(7) \\
\text { MV } \\
\text { Probit }\end{array}$ & \\
\hline \multicolumn{9}{|l|}{ i. FSC Archetype } \\
\hline $\begin{array}{l}\text { DIST } \\
\text { DIST }^{2} \\
\text { INCOME } \\
\text { NETWORK } \\
\text { PAX } \\
\text { HHI }\end{array}$ & $\begin{array}{l}0.6511^{* * *} \\
-0.1910^{* * *} \\
0.0029^{* * *} \\
0.0202^{* * *} \\
1.2586^{* * *} \\
-0.0171^{* * *}\end{array}$ & $\begin{array}{c}1.3332^{* * *} \\
-0.3905^{* * *} \\
0.0108^{* * *} \\
0.0380^{* * *} \\
2.3569^{* * *} \\
-0.0299^{* * *}\end{array}$ & $\begin{array}{r}0.5971^{* * *} \\
-0.1830^{* * *} \\
0.0916^{* * *} \\
0.0092^{* * *} \\
1.1634^{* * *} \\
-0.0193^{* * *}\end{array}$ & $\begin{array}{r}1.2118^{* * *} \\
-0.3726^{* * *} \\
0.1917^{* * *} \\
0.0164^{* * *} \\
2.0509^{* * *} \\
-0.0347^{* * *}\end{array}$ & $\begin{array}{r}0.6014^{* * *} \\
-0.1832^{* * *} \\
0.1023^{* * *} \\
0.0080^{* * *} \\
1.1987^{* * *} \\
-0.0193^{* * *}\end{array}$ & $\begin{array}{r}1.2162^{* * *} \\
-0.3716^{* * *} \\
0.2041^{* * *} \\
0.0148^{* * *} \\
2.1350^{* * *} \\
-0.0344^{* * *}\end{array}$ & $\begin{array}{r}0.7050^{* * *} \\
-0.2174^{* * *} \\
0.1796^{* * *} \\
-0.0123^{* * *} \\
1.1163^{* * *} \\
-0.0209^{* * *}\end{array}$ & ! \\
\hline \multicolumn{9}{|l|}{ ii. LCC Archetype } \\
\hline $\begin{array}{l}\text { DIST } \\
\text { DIST }^{2} \\
\text { INCOME }_{\text {NETWORK }} \\
\text { PAX } \\
\text { HHI }\end{array}$ & $\begin{array}{r}0.8172^{* * *} \\
-0.0935^{* * *} \\
-0.1189^{* * *} \\
0.0774^{* * *} \\
1.0544^{* * *} \\
-0.0234^{* * *}\end{array}$ & $\begin{array}{r}1.5077^{* * *} \\
-0.1664^{* * *} \\
-0.2324^{* * *} \\
0.1354^{* * *} \\
2.2222^{* * *} \\
-0.0375^{* * *}\end{array}$ & $\begin{array}{r}1.3280^{* * *} \\
-0.2683^{* * *} \\
-0.1906^{* * *} \\
0.0802^{* * *} \\
0.9787^{* * *} \\
-0.0272^{* * *}\end{array}$ & $\begin{array}{r}2.5221^{* * *} \\
-0.5084^{* * *} \\
-0.3640^{* * *} \\
0.1432^{* * *} \\
2.1363^{* * *} \\
-0.0440^{* * *}\end{array}$ & $\begin{array}{r}1.5988^{* * *} \\
-0.3287^{* * *} \\
-0.0684^{* * *} \\
-0.0007^{* * *} \\
1.1509^{* * *} \\
-0.0339^{* *}\end{array}$ & $\begin{array}{l}2.9772^{* * *} \\
-0.6121^{* * *} \\
-0.1460^{* * *} \\
-0.0005 \\
2.5015^{* * *} \\
-0.0549^{* * *}\end{array}$ & $\begin{array}{r}1.5954^{* * *} \\
-0.3290^{* * *} \\
-0.0590^{* * *} \\
-0.0070^{* *} \\
1.2454^{* * *} \\
-0.0306^{* * *}\end{array}$ & 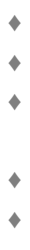 \\
\hline \multicolumn{9}{|l|}{ iii. RGC Archetype } \\
\hline $\begin{array}{l}\text { DIST } \\
\text { DIST }^{2} \\
\text { INCOME } \text { NETWORK } \\
\text { PAX } \\
\text { HHI }\end{array}$ & $\begin{array}{r}1.2156^{* * *} \\
-1.5425^{* * *} \\
0.1382^{* * *} \\
0.1072^{* * *} \\
0.0443^{* * *} \\
-0.0035^{* * *}\end{array}$ & $\begin{array}{r}2.5681^{* * *} \\
-3.1541^{* * *} \\
0.2980^{* * *} \\
0.1817^{* * *} \\
0.1039^{* * *} \\
-0.0031^{*}\end{array}$ & $\begin{array}{c}1.0514^{* * *} \\
-1.6227^{* * *} \\
0.2639^{* * *} \\
0.1071^{* * *} \\
0.0794^{* * *} \\
-0.0001\end{array}$ & $\begin{array}{c}2.5249^{* * *} \\
-3.5534^{* * *} \\
0.5559^{* * *} \\
0.1864^{* * *} \\
0.1681^{* * *} \\
0.0030^{*}\end{array}$ & $\begin{array}{c}1.6562^{* * *} \\
-2.1108^{* * *} \\
0.3057^{* * *} \\
0.0501^{* * *} \\
0.1448^{* * *} \\
0.0008\end{array}$ & $\begin{array}{c}1.7362^{* * *} \\
-2.1638^{* * *} \\
0.3126^{* * *} \\
0.0489^{* * *} \\
0.1554^{* * *} \\
0.0021^{* *}\end{array}$ & $\begin{array}{c}1.3358^{* * *} \\
-1.8964^{* * *} \\
0.3065^{* * *} \\
0.0468^{* * *} \\
0.1546^{* * *} \\
0.0010\end{array}$ & 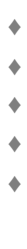 \\
\hline $\begin{array}{l}\text { Controls } \\
\text { Regional effects } \\
\text { Seasonality \& trend }\end{array}$ & $\begin{array}{l}\text { no } \\
\text { no }\end{array}$ & $\begin{array}{l}\text { no } \\
\text { no }\end{array}$ & $\begin{array}{c}\text { yes } \\
\text { no }\end{array}$ & $\begin{array}{c}\text { yes } \\
\text { no }\end{array}$ & $\begin{array}{l}\text { yes } \\
\text { yes }\end{array}$ & $\begin{array}{l}\text { yes } \\
\text { yes }\end{array}$ & $\begin{array}{l}\text { yes } \\
\text { yes }\end{array}$ & \\
\hline \multicolumn{9}{|l|}{$\begin{array}{l}\text { Cross-equations tests of } \\
\text { equality of parameters (chi2) }\end{array}$} \\
\hline $\begin{array}{l}\text { (i) FSC Arch. = (ii) LCC Arch. } \\
\text { (i) FSC Arch. = (iii) RGC Arch. } \\
\text { (ii) LCC Arch. = (iii) RGC Arch. }\end{array}$ & $\begin{array}{l}659.58^{* * *} \\
739.62^{* * *} \\
723.45^{* * *}\end{array}$ & $\begin{array}{l}716.62^{* * *} \\
683.51^{* * *} \\
597.53^{* * *}\end{array}$ & $\begin{array}{l}460.72^{* * *} \\
712.91^{* * *} \\
717.07^{* * *}\end{array}$ & $\begin{array}{l}524.69^{* * *} \\
714.32^{* * *} \\
656.82^{* * *}\end{array}$ & $\begin{array}{l}738.99^{* * *} \\
443.33^{* * *} \\
767.42^{* * *}\end{array}$ & $\begin{array}{l}762.52^{* * *} \\
398.96^{* * *} \\
707.27^{* * *}\end{array}$ & $\begin{array}{l}1365.26^{* * *} \\
3413.19^{* * *} \\
4837.95^{* * *}\end{array}$ & \\
\hline $\begin{array}{lr}\text { Pseudo R2 Statistic } & \text { (i) } \\
& \text { (ii) } \\
& \text { (iii) } \\
\text { overall } \\
\text { Nr Observations }\end{array}$ & $\begin{array}{l}0.3373 \\
0.4798 \\
0.2894 \\
40,292\end{array}$ & $\begin{array}{l}0.3399 \\
0.4823 \\
0.2744 \\
40,292\end{array}$ & $\begin{array}{l}0.3863 \\
0.5146 \\
0.3776 \\
40,292\end{array}$ & $\begin{array}{l}0.3885 \\
0.5176 \\
0.3708 \\
40,292\end{array}$ & $\begin{array}{l}0.3881 \\
0.5763 \\
0.4677 \\
40,292\end{array}$ & $\begin{array}{l}0.3901 \\
0.5799 \\
0.4646 \\
40,292\end{array}$ & $\begin{array}{l}0.5719 \\
40,292\end{array}$ & \\
\hline
\end{tabular}

Notes: p-value representations: $* * * p<0.01, * * p<0.05, * p<010$. ' $2 D C$ ' means Two-Dimension-Clustered Standard Errors Probit or Logit. 'IV' means Instrumental Variables. The symbol ' indicates the rows in which all models agree in terms of sign and significance of the respective coefficient. We report McFadden's pseudo $R^{2}$ for all specifications. 
Lastly, we focus on the cross-equations tests for equality of parameters, also shown in Table 2 . We note that, for all model specifications and all combinations of pairs of archetypes, the tests rejected the null hypothesis of equality of parameters. In this way, these results suggest that all of the three chosen archetypes present different network-design behaviors and thus produce distinct network development patterns.

\subsection{Network design drivers}

\subsubsection{Archetypical blends and their evolution}

Next, we assess the network-design decompositions into archetypes' rationales of the investigated Brazilian carriers. Table 3 presents the estimation results, with Column (6) presenting our preferred model, related to the multivariate probit specification with a time trend and control variables related to seasonal and regional effects. As in the first stage, all specifications presented control for twodimension-clustered standard errors at the city-of-origin/time and city-of-destination/time levels. We note some instances of archetypes and interacted variables produced by the first stage estimators presenting some differing effects in the second stage whether the model utilized was the probit or the logit, as seen in Columns (1) to (4), which test combinations of these models. Given this, we will focus our discussion on the coefficients that had unanimous effects over all of the specifications. ${ }^{13}$

Proceeding to the analysis of the model associated with Azul, unanimous results suggest that the company's network started as a mixture of the RGC archetype and, to a much larger extent, the LCC archetype, at least during its first months of operation. Along its trajectory, nevertheless, the company seems to have diverged from its initial baseline, as indicated by the negative coefficients associated with the corresponding trend-interacted variables (PrArch_LCC $\times$ TREND and PrArch_RGC $\times$ TREND), with its LCC character reducing at a faster rate. Gol's model indicates that the company may be represented by the LCC archetype, although noticeably influenced by the FSC business model when performing its network-design decisions. Over time, nevertheless, the specifications do not seem to have found any consensus towards which archetype the company converged or diverged. Regarding Avianca's model, the results find agreement on the decomposition of the airline's network behavior as an RGC carrier. Moreover, trend-interacted variables suggest an increasing alignment of the company with the LCC archetype, at least from a network perspective. In addition, LATAM's model indicates that, while the company began predominantly as an FSC, avoiding RGC network strategies (with no consensus being found regarding its relation with the LCC model), it converged more and more towards the RGC archetype - as per the trend-interacted variable PrArch_RGC $\times$ TREND. 
Table 3 - Estimation results of the $2^{\text {nd }}$ stage (network design drivers)

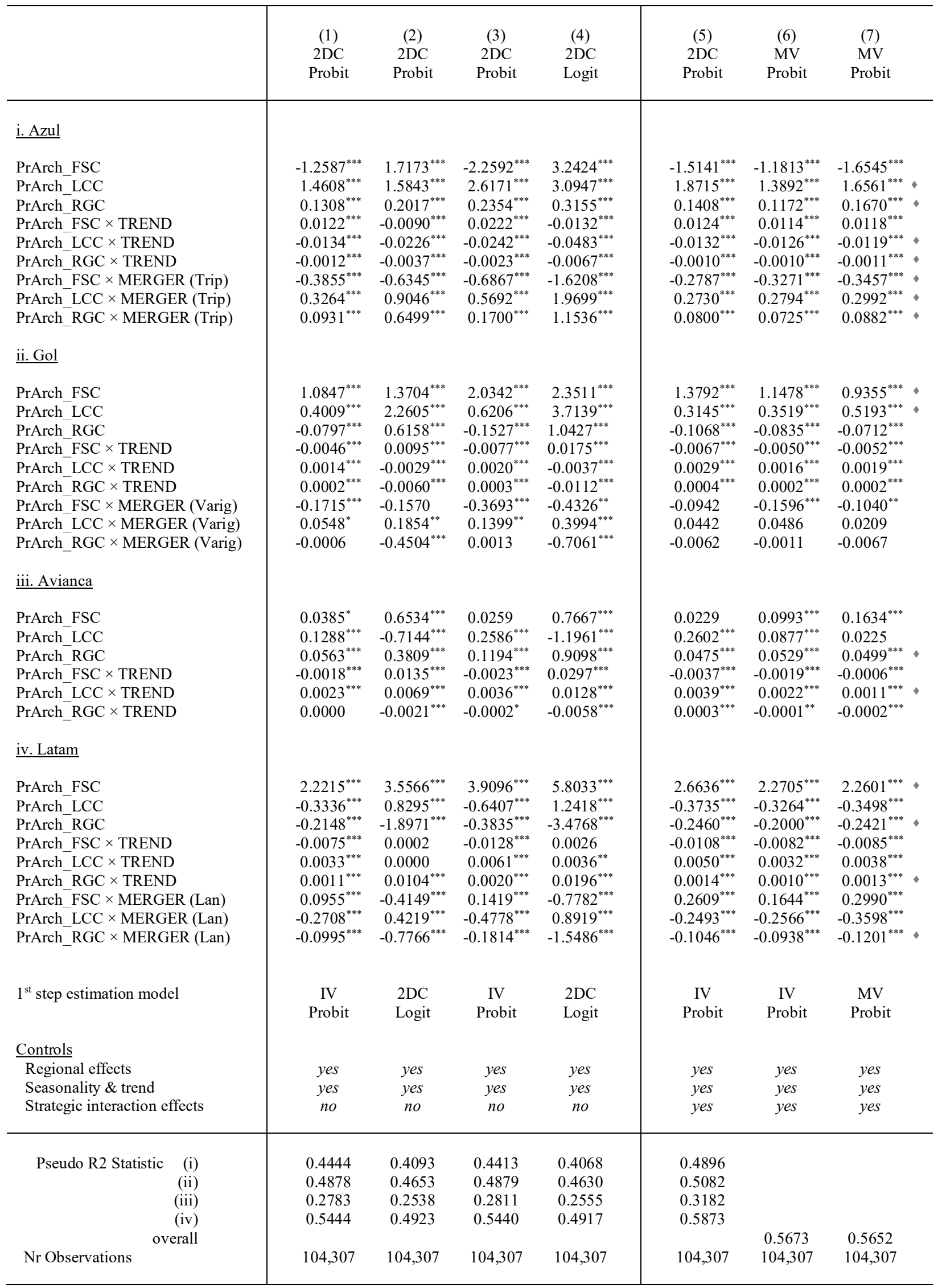

Notes: p-value representations: ${ }^{* *} p<0.01, * * p<0.05,{ }^{*} p<010 .{ }^{\prime} 2 D C^{\prime}$ means Two-Dimension-Clustered Standard Errors Probit or Logit; 'MV Probit' means Multivariate Probit. 'PrArch' means predicted values lagged by a quarter. The symbol ' $\$$ ' indicates the rows in which all models agree in terms of sign and significance of the respective coefficient. We report McFadden's pseudo $R^{2}$ for all specifications. 


\subsubsection{Influences from consolidations}

Turning our attention to the possible influences of the consolidation events on business models' and networks' structural breaks, we notice that no clear general pattern appears to have emerged for this set of firms. In the case of Gol, no consensus is found among specifications. In contrast, TAM's merger with LAN in 2010, associated with a deviation from the RGC archetype, could be interpreted in the following way. One could argue that the merged company decided to redeploy much of its resources to serve a new — and possibly more profitable — customer base. This would take place only in the short run, however, mainly due to financial restrictions for the company to set the appropriate structure to maintain the two niches. This conjecture does find support on the rising RGC archetype trend included in LATAM's model, which would cover its long-run effect. We make the additional remark that from a network-planning point of view, their joint efforts, which resulted in Latin America's largest airline, probably brought the resulting carrier closer to the FSC archetype. On the other hand, the structural break related to Azul's acquisition of regional carrier Trip readily agrees with the discussions presented in Section 3, as it appears to be associated with a greater inclination by the resulting carrier towards the RGC archetype - compared to Azul's original business model. Convergence towards the LCC archetype and divergence from the FSC archetype are noticed for this carrier as well. Based on how these results partially agree with our ex-ante expectations, we are compelled to reject neither hypothesis $\mathbf{H}_{1}$ nor hypothesis $\mathbf{H}_{2}$, i.e., that airlines' networks can, indeed, be decomposed as a blend of archetypical ones and that the time evolution of their business models can be identified and, furthermore, that the consolidation events have had disruptive effects on the ongoing orientations of these carriers.

\subsubsection{Correlation coefficients}

Finally, concerning the correlation coefficients produced by the multivariate probit framework in Column (6) of Table 3, the results can be found in Table 4. We note, however, that the results concerning idiosyncratic sources of profitability of the firms were negatively correlated among each pair of airlines, implying that, as much as they could, these firms tried to differentiate themselves and operate in markets not shared with competitors. 
Table 4 - Estimation results of the $2^{\text {nd }}$ stage (correlations between rivals' choices)

\begin{tabular}{l|cccc}
\hline & (1) & $(2)$ & $(3)$ & (4) \\
& Azul & Gol & Avianca & LATAM \\
\hline (1) Azul & - & - & - & - \\
(2) Gol & $-0.3381 * * *$ & - & - & - \\
(3) Avianca & $-0.4404^{* * *}$ & $-0.0981^{* * *}$ & - & - \\
(4) LATAM & $-0.3339 * * *$ & $-0.0863 * * *$ & $-0.4062 * * *$ & - \\
\hline
\end{tabular}

Notes: p-value representations: ${ }^{* *} p<0.01,{ }^{* *} p<0.05, * p<010$. Results extracted from Table 3, Column (6). Likelihood ratio test statistic of all correlations jointly equal to zero: $\chi^{2}(6)=9539.34^{* * *}$.

Furthermore, turning our focus once again to Table 3, we note that the specification in Column (5) differs from the one in Column (1) by the inclusion of the strategic interaction dummies (dummies of rivals). The coefficients of these dummies are not shown here, as results for strategic interactions between rivals in this model are contaminated by endogeneity issues. We only highlight how the specification have demonstrated similar results when compared with the one presented in Column (6). Furthermore, the same remark also applies for the similarity of results between Columns (6) and (7), the latter related to a specification having the multivariate probit framework in both stages. In closing, we point out that the robustness checks associated with probit specifications in Columns (1) and (3) in Table 3, which do not consider rival influences, do not differ significantly from our main model as well.

\section{Discussion and conclusion}

This paper aimed at estimating the critical drivers regarding the network-planning decisions of major airlines in Brazil. We considered the cases of Avianca, Azul, Gol, and LATAM and examined their differences in terms of business models, size and market positioning, with a particular focus on their network rationales over time. We also examined the network patterns of conceived business model archetypes.

Our proposed two-stage methodology for empirical airline business model identification consisted of a sequence of econometric models where the actual network-related decisions of both virtual business model archetypes and existing carriers were estimated. We considered the possibility of a dynamic network-design pattern in which one of the outcomes could be that the existing networks were strategically designed as a blend of archetypical ones. We find, considering only the unanimous 
results among specifications, that each firm appears to have positioned itself through time at a particular intersection of at least two business models: Gol with a (fixed) mix between LCC and FSC; LATAM, with a fixed FSC part and an initially negative, although increasing RGC part; Avianca, with a fixed RGC part and an increasing LCC part; and, finally, Azul, with a fixedalthough decreasing in time-LCC and RGC combination.

Moreover, during the 18-year span from 2001 to 2018, many changes in the business models of the analyzed carriers and the competitive landscape of the Brazilian air transportation industry unfolded. These changes included the bankruptcy of Varig, as well as three major consolidation events (Gol and Varig, Azul and Trip, TAM and LAN) that took place during that period. In this respect, mergers in the Brazilian aviation industry seem diverse in the way they directed the merging parts' network configurations, and hence, to some extent, their business reorientations. These appear to have been dependent on the underlying business models (or business model blends) of the participant carriers, in particular that of the carrier being acquired and/or the smallest of the merging parts, which may have served as a stepping stone for the largest carrier's repositioning in the market. Gol's acquisition of Varig, nevertheless, did not present unchallenged results among specifications, and, as such, further investigation should be conducted in this respect.

In terms of policy implications, the paper sheds light on the potential consequences that adjustments in airline business models and/or consolidations may bring in terms of network design. While the paper does not necessarily bring any novel results that would significantly shift policies in this domain, it does support findings from previous research in the areas of network design, airport access and airline consolidation. Some of the issues that planners might want to consider include:

- The effects of innovative business models on the development and upgrading of airports: This is illustrated by the surge of Azul airlines in the Campinas/Viracopos airport, a traditional air cargo terminal and second-tier airport in terms of passenger numbers. Azul's blend of low fares together with a connection-oriented network structure was key for the increased passenger numbers at this airport, which witnessed a ten-fold growth in the period from 2008 to 2014, following its choice as the airline's main hub (Source: data from ANAC's Air Transport Statistical Database, 2008-2014). As a result, not only was Viracopos' otherwise less sought-after infrastructure better utilized, but this initiative also made it sufficiently viable and attractive for inclusion in part of an airport privatization process that took place in Brazil.

- The role of business models on the viability of new airport infrastructure: The business models of potential airlines to be attracted to a new airport must be taken into account before 
the actual construction of the necessary infrastructure, as the airport's location and its design can favor (or hinder) particular business models (Papatheodorou \& Lei, 2006; Gillen \& Hazledine, 2015). A shift from a 'build and they will come' mindset is critical for future airport planning at a macro/national level.

- The effects of consolidations on airport infrastructure development: Airline mergers and acquisitions, along with changes in network structure design, may impose severe risks associated with the forecast of airport infrastructure development, as the consolidation of networks in fewer, more concentrated hubs can lead to the abrupt closure of individual routes with significant impacts to airports - especially regional ones.

\subsection{Limitations and future research}

As a major limitation of our empirical approach, we found that many key regressors were sensitive to changes in the specification of the model. As discussed before, we systematically tested the robustness of our results across alternative models. Based on the experiments, we found suggestive evidence that the degree of model robustness with respect to the currently used variables was $78 \%$ for Stage 1 (i.e., 14 out of 18 variables had consistent results among the alternative models), but only $45 \%$ for Stage 2 (i.e., 15 out of 33 variables). Although some important results could be extracted from the variables that were not sensitive at all, we acknowledge that further investigation into the behavior of firms regarding the available business models' archetypes is needed. A noteworthy extension of our research would be the addition of a broader set of regressors in the first stage, as the variables that we used for archetypical network-design rationales may not have captured the complexity of the problem. The use of a reduced number of regressors was devised to treat the archetypes as independent as possible of idiosyncratic behaviors of the companies chosen to represent them. Nevertheless, the inclusion of potentially highly correlated pairs of variables such as DIST, DIST ${ }^{2}$ and PAX, HHI is not without objections. Furthermore, utilizing the maximum personal income and number of connections between the origin and destination cities of a route, while capturing to some extent the centrality of an airport for an airline's network, has the disadvantage of not fully controlling for the demographic and economic characteristics of the endpoints' economies.

In addition, we are aware of the limitations of the framework employed in Stage 2. In a market in which the behavior of each firm is strategically dictated by its interaction with other decisionmakers, a more theoretically driven approach would play an important role. An empirical methodology based on oligopolistic equilibrium concepts in which the simultaneity of profits and market structure is explicitly accounted for would allow for a more direct economic interpretation 
of the estimated coefficients (Berry, 1992). Still, the estimation of such structural models of entry is not per se immune to criticism. Berry \& Reis (2007) note that inferences based on structural models of market structure may also be very sensitive to a small change in assumptions, such as the timing of moves or the solution concept of the game. Additionally, the authors describe that with firm heterogeneity, entry models can present multiple equilibria or no equilibrium at all, with the key economic parameters not being identifiable. In many cases, simplifications of assumptions and/or reductions of dimensionality of the underlying game must be imposed (Berry \& Reis, 2007; Aguirregabiria \& Ho, 2012). To both enhance model simplicity and allow for flexibility in the estimation of the correlations among firms' decisions across time, we did not impose an oligopolistic equilibrium in our model. Instead, we kept our focus on the role of the existing business model benchmarks on airlines' decisions when setting their networks. We call these benchmarks as 'archetypes' and consider their formation as sufficiently exogenous to the prevailing market structure at the time network decision-making processes are made - the 'testing' sample period. We aimed at uncovering whether firms sought to explore markets consistently with those exogenous archetypes. In this sense, our empirical framework constitutes a reduced-form model of the underlying status of competition in the market as captured by the estimated parameters. We contend that the possible confounding effect of 'archetype-blend' selection with strategic rivalry by carriers may produce market outcomes in the same direction, namely, either business model convergence or divergence.

In closing, we point out that our results are confined to the experience of the Brazilian air transportation industry, particularly associated with a snapshot of the period 2001-2018. Due to this setting, we have benefited from analyzing this industry from the beginning of its deregulation process. We were able to observe distinct business model archetypes, as Brazilian airlines were still tweaking their operational characteristics. More broadly, however, as companies constantly adapt to the market, archetypes become harder to be found - not surprisingly, they themselves become subject to changes.

In this way, future research from a network design point of view in contexts such as the U.S. and Europe, where a broader array of carriers is available, could provide an interesting ramification, possibly put into practice by the creation of archetypes as 'external constructs.' Although conformance of these carriers to business model archetypes would probably be manifested to a lesser extent, given the comparatively longer period since their inceptions following deregulation in these markets, 'external archetypes' could be formed from a set of carriers by capturing their mean behavior, enabling them to be as free from idiosyncratic influences as possible. We believe that further investigation into this issue should be undertaken, with econometric models aiming at a better understanding of the way carriers adapt their businesses to their environments and to their rivals, as 
well as how they may exploit the opportunities set out by consolidations in deregulated airline markets.

\section{References}

Aguirregabiria, V., \& Ho, C. Y. (2012). A dynamic oligopoly game of the U.S. airline industry: Estimation and policy experiments. Journal of Econometrics, 168(1), 156-173.

Armantier, O., \& Richard, O. (2008). Domestic airline alliances and consumer welfare. The RAND Journal of Economics, 39(3), 875-904.

Baker, D., \& Donnet, T. (2012). Regional and remote airports under stress in Australia. Research in Transportation Business \& Management, 4, 37-43.

Barros, V. G. (2012). Transportation choice and tourists' behaviour. Tourism Economics, 18(3), 519531.

Belloni, A., Chen, D., Chernozhukov, V., \& Hansen, C. (2012). Sparse models and methods for optimal instruments with an application to eminent domain. Econometrica, 80(6), 2369-2429.

Berry, S. (1992). Estimation of a Model of Entry in the Airline Industry. Econometrica, 60(4), 889917.

Berry, S., \& Reiss, P. (2007). Empirical models of entry and market structure. Handbook of Industrial Organization, 3, 1845-1886.

Bilotkach, V., \& Pai, V. (2014). Hubs versus airport dominance. Transportation Science, 50(1), 166179.

Blackstone, E. A., Buck, A. J., \& Hakim, S. (2006). Determinants of airport choice in a multi-airport region. Atlantic Economic Journal, 34(3), 313-326.

Boguslaski, C., Ito, H., \& Lee, D. (2004). Entry patterns in the southwest airlines route system. Review of Industrial Organization, 25(3), 317-350.

Borenstein, S., \& Rose, N. L. (1994). Competition and price dispersion in the U.S. airline industry. Journal of Political Economy, 102(4), 653-683.

Busse, M. (2002). Firm financial condition and airline price wars. RAND Journal of Economics, 298-318.

Butler, J. S., \& Moffitt, R. (1982). A computationally efficient quadrature procedure for the onefactor multinomial probit model. Econometrica: Journal of the Econometric Society, 761-764.

Cameron, A. C., Gelbach, J. B., \& Miller, D. L. (2006). Bootstrap-based improvements for inference with clustered errors, University of California (pp. 06-21). Davis working paper.

Cameron, A. C., Gelbach, J. B., \& Miller, D. L. (2011). Robust inference with multiway clustering. Journal of Business \& Economic Statistics, 29(2), 238-249.

Cappellari, L., \& Jenkins, S. P. (2006). Calculation of multivariate normal probabilities by simulation, with applications to maximum simulated likelihood estimation. The Stata Journal, 6(2), 156-189.

Crowley, F., \& Jordan, D. (2017). Does more competition increase business-level innovation? Evidence from domestically focused firms in emerging economies. Economics of Innovation and New Technology, 26(5), 477-488.

Daft, J., \& Albers, S. (2013). A conceptual framework for measuring airline business model convergence. Journal of Air Transport Management, 28, 47-54. 
Daft, J., \& Albers, S. (2015). An empirical analysis of airline business model convergence. Journal of Air Transport Management, 46, 3-11.

de Wit, J. G., \& Zuidberg, J. (2012). The growth limits of the low cost carrier model. Journal of Air Transport Management, 21, 17-23.

Doganis, R. (2006) The Airline Business, 2nd edition. London: Routledge.

Dresner, M., Windle, R., \& Yao, Y. (2002). Airport Barriers to Entry in the U.S. Journal of Transport Economics and Policy, 36(3), 389-405.

Evangelho, F., Huse, C., \& Linhares, A. (2005). Market entry of a low cost airline and impacts on the Brazilian business travelers. Journal of Air Transport Management, 11(2), 99-105.

Evans, W. N., Froeb, L. M., \& Werden, G. J. (1993). Endogeneity in the concentration--Price relationship: Causes, consequences, and cures. The Journal of Industrial Economics, 431-438.

Fageda, X., Suau-Sanchez, P., \& Mason, K. J. (2015). The evolving low-cost business model: Network implications of fare bundling and connecting flights in Europe. Journal of Air Transport Management, 42, 289-296.

Faust, O., Gönsch, J., \& Klein, R. (2017). Demand-oriented integrated scheduling for point-to-point airlines. Transportation Science, 51(1), 196-213.

Franke, M. (2004). Competition between network carriers and low-cost carriers-retreat battle or breakthrough to a new level of efficiency? Journal of Air Transport Management, 10(1), 1521.

Gerardi, K. S., \& Shapiro, A. H. (2009). Does competition reduce price dispersion? New evidence from the airline industry. Journal of Political Economy, 117(1), 1-37.

Gillen, D., \& Gados, A. (2008). Airlines within airlines: Assessing the vulnerabilities of mixing business models. Research in Transportation Economics, 24(1), 25-35.

Gillen, D., \& Hazledine, T. (2015). The economics and geography of regional airline services in six countries. Journal of Transport Geography, 46, 129-136.

Gillen, D., \& Morrison, W. G. (2005). Regulation, competition and network evolution in aviation. Journal of Air Transport Management, 11(3), 161-174.

Gil-Moltó, M. J., \& Piga, C. A. (2008). Entry and exit by European low-cost and traditional carriers. Tourism Economics, 14(3), 577-598.

Graf, L. (2005). Incompatibilities of the low-cost and network carrier business models within the same airline grouping. Journal of Air Transport Management, 11(5), 313-327.

Greene, W. H. (2018). Econometric Analysis. 8th edition. New Jersey: Pearson.

Guan, J. \& Petersen, M. (2008) Probit2.ado. Stata user-written program.

Henrickson, K. E., \& Wilson, W. W. (2016). The convergence of low-cost and legacy airline operations. In Airline Efficiency (pp. 355-375). Emerald Group Publishing Limited.

Holloway, S. (2008). Straight and Level: Practical Airline Economics. Aldershot, Hampshire: Ashgate.

Huse, C., \& Evangelho, F. (2007). Investigating business traveller heterogeneity: Low-cost vs fullservice airline users? Transportation Research Part E: Logistics and Transportation Review, 43(3), 259-268.

Jean, D. A., \& Lohmann, G. (2016). Revisiting the airline business model spectrum: The influence of post global financial crisis and airline mergers in the U.S. (2011-2013). Research in Transportation Business \& Management, 21, 76-83. 
Klophaus, R., Conrady, R., \& Fichert, F. (2012). Low cost carriers going hybrid: Evidence from Europe. Journal of Air Transport Management, 23, 54-58.

Koo, T. T., \& Lohmann, G. (2013). The spatial effects of domestic aviation deregulation: A comparative study of Australian and Brazilian seat capacity, 1986-2010. Journal of Transport Geography, 29, 52-62.

Lange, A., \& Bier, T. (2019). Airline business models and their network structures. Logistics Research, 12, 1-14.

Lindstädt, H., \& Fauser, B. (2004). Separation or integration? Can network carriers create distinct business streams on one integrated production platform? Journal of Air Transport Management, 10(1), 23-31.

Lohmann, G., \& Koo, T. T. (2013). The airline business model spectrum. Journal of Air Transport Management, 31, 7-9.

Ma, W., Wang, Q., Yang, H., \& Zhang, Y. (2020). Is multimarket contact an antitrust concern? A case of China's airline market. Transportation Research Part A: Policy and Practice, 132, $515-$ 526.

Mason, K. J. (2001). Marketing low-cost airline services to business travellers. Journal of Air Transport Management, 7(2), 103-109.

Mason, K. J., \& Morrison, W. G. (2008). Towards a means of consistently comparing airline business models with an application to the 'low cost' airline sector. Research in Transportation Economics, 24(1), 75-84.

Milioti, C. P., Karlaftis, M. G., \& Akkogiounoglou, E. (2015). Traveler perceptions and airline choice: A multivariate probit approach. Journal of Air Transport Management, 49, 4652.Morrell, P. (2005). Airlines within airlines: An analysis of U.S. network airline responses to Low Cost Carriers. Journal of Air Transport Management, 11(5), 303-312.

Müller, K., Hüschelrath, K., \& Bilotkach, V. (2012). The construction of a Low-Cost airline network - Facing competition and exploring new markets. Managerial and decision economics, 33(78), 485-499.

Oliveira, A. V. M. (2008). An empirical model of low-cost carrier entry. Transportation Research Part A: Policy and Practice, 42(4), 673-695.

Papatheodorou, A., \& Lei, Z. (2006). Leisure travel in Europe and airline business models: A study of regional airports in Great Britain. Journal of Air Transport Management, 12(1), 47-52.

Roucolle, C., Seregina, T., \& Urdanoz, M. (2020). Measuring the development of airline networks: Comprehensive indicators. Transportation Research Part A: Policy and Practice, 133, 303-324.

Thompson, I. B. (2002). Air transport liberalization and the development of third level airports in France. Journal of transport geography, 10(4), 273-285.

Thompson, S. B. (2011). Simple formulas for standard errors that cluster by both firm and time. Journal of Financial Economics, 99(1), 1-10.

Varella, R. R., Frazão, J., \& Oliveira, A. V. (2017). Dynamic pricing and market segmentation responses to low-cost carrier entry. Transportation Research Part E: Logistics and Transportation Review, 98, 151-170.

Whyte, R., \& Lohmann, G. (2015). The carrier-within-a-carrier strategy: An analysis of Jetstar. Journal of Air Transport Management, 42, 141-148.

Yasar, M. (2013). Political influence of exporting and import-competing firms: Evidence from eastern European and central Asian countries. World Development, 51, 154-168. 
${ }^{1}$ We also mention results by Evangelho et al. (2005), indicating the role of culture in the preference for FSCs by business travelers of large organizations, and those of Huse \& Evangelho (2007), which suggest that these passengers tend to reassess their valuation of some product attributes more favorably to LCCs after having experienced their services.

2 "Ryanair's business class" - The Economist, Feb. 28, 2013.

3 "Norwegian might still transform long-haul flying" - The Economist, Jul. 13, 2017.

4 "With its Cost Advantage Eroded, Southwest Forced to Aim for International Markets" - Forbes, Nov. 2, 2016.

${ }^{5}$ For an examination of the connection between airline networks and their business models, the reader is referred to Gillen \& Morrison (2005). Moreover, an interesting account of particular characteristics of point-to-point network planning may be found in Faust et al. (2017).

6 "Flag carriers try to stay competitive by learning from the budget Airlines" - The New York Times, Nov. 5, 2008.

${ }^{7}$ Gol and TAM used to split almost evenly the largest airports and densest routes in the Brazilian domestic market. By that time, these companies benefitted from limited competition, stemming from either smaller mainline or regional carriers.

${ }^{8}$ Gol Intelligent Airlines Inc. (30 Apr 2018) United States Securities and Exchange Commission - FORM 20-F. Available at www.sec.gov.

9 Azul S.A. (30 Apr 2019) United States Securities and Exchange Commission - FORM 20-F. Available at www.sec.gov.

${ }^{10}$ As suggested by their public statements, found at Avianca's website (www.avianca.com.br) and Azul S.A. (27 Apr 2018) United States Securities and Exchange Commission - FORM 20-F (available at www.sec.gov).

${ }^{11}$ The estimated Kleibergen-Paap rk Wald F statistics were 12,047 (FSC), 17,071 (LCC) and 70,566 (RGC).

${ }^{12}$ The results without considering these lags did not differ significantly from the ones presented in the text.

${ }^{13}$ We note that a 'pairs bootstrap' procedure with a strata approach was also employed, consisting of 250 replications for the results of the second stage models. Results pertaining to the statistical significance of the coefficients, nevertheless, were the same as those obtained without the procedure. 


\section{Appendix}

A network-design analysis of airline business model adaptation in the face of competition and consolidation

Renan P. de Oliveira

Alessandro V. M. Oliveira

Gui Lohmann 


\section{Appendix - Description of data and variables}

We define a route as a directional city-pair market associated with the movement of scheduled revenue passengers in a given month. The dataset consists of 2,613 distinct domestic routes in Brazil and 154,281 route/year observations overall, with 40,292 observations used for the $1^{\text {st }}$ methodological stage and 113,989 observations used in the $2^{\text {nd }}$ stage. Our primary data sources are the National Civil Aviation Agency (ANAC) and the Brazilian Institute of Geography and Statistics (IBGE).

The variables and controls utilized in the $1^{\text {st }}$ stage regressions are the following:

- DIST is a variable measuring the Vincenty distance in kilometers between the endpoints of route $i$. This is an average value, as some cities are associated with more than one airport. It is included to assess the impact of a route's distance on a given archetype's route selection criteria. Furthermore, this variable is also employed for capturing the use of connecting flights on these archetypes' network configurations.

- $D I S T^{2}$ is a variable measuring the square of the distance in kilometers between the endpoints of route $i$. This variable is considered to allow for a possibly nonlinear relationship between the route's length and the archetype's presence.

- $I N C O M E=\max \left(G D P P C_{a_{o}} ; G D P P C_{a_{d}}\right)$ is a function with inputs corresponding to the GDPs per capita (in billion R\$) associated with the origin and destination cities of a given route $i$ at a given period $t$, pertaining to archetype $a$ 's network (GDPPC $C_{a_{o}}$ and $G D P P C_{a_{d}}$, respectively). This function returns the maximal value between these two quantities, with lagged values of 12 months being employed (to better represent the network planning horizon of carriers). It is adjusted by a deflator based on the Broad Consumer Price Index (IPCA), to a value comparable to January 2019. For the computation of the GDPs, we considered the entire geographic area of a mesoregion as defined by the Brazilian Institute of Geography and Statistics (IBGE), with São Paulo cities having additional mesoregions. Source: (IBGE).

- $N E T W O R K=\max \left(D_{a_{o}} ; D_{a_{d}}\right)$ is a function with inputs corresponding to the number of destinations associated with the origin and destination airports of a given route $i$ at a given period $t$, pertaining to archetype $a$ 's network ( $D_{a_{o}}$ and $D_{a_{d}}$, respectively). Similarly to the previous variable, this function returns the maximal value between these two quantities lagged by 12 months. It is used to assess the centrality of a set of airports for archetype $a$ 's network. 
- $\quad H H I$ is the Herfindahl-Hirschman index (HHI) of concentration of revenue passengers on the route (multiplied by 100), treated as an endogenous regressor. To extract this measure, we consider the city-pair level market shares of passengers of the participating carriers. ${ }^{1}$

- $P A X$ is the average number of daily revenue passengers on the route (in tens of thousands), which is our measure of city-pair traffic density. ${ }^{1}$ This variable is treated as an endogenous regressor.

- Regional dummies, equal to $\mathbb{1}_{r_{o}}(i)$ and $\mathbb{1}_{r_{d}}(i)$, are sets of controls for origin and destination regions $r_{o}, r_{d} \in R=\{C W, N E, N W, S E, S W\}$. For a fixed origin region $r_{o}$, the function $\mathbb{1}_{r_{o}}(i)$ takes on the value 1 (one) if route $i$ has its origin pertaining to it $\left(i \in r_{o}\right)$ and 0 (zero) otherwise. Destination regions are defined similarly.

- Seasonality and time trend terms are also considered to control for periods of expansion and contraction of these archetypes' networks.

The variables and controls utilized in the $2^{\text {nd }}$ stage regressions are the following:

- PrArch_FSC,PrArch_LCC and PrArch_RGC are the predictions for the latent expected profit variables associated with the 'FSC', 'LCC' and 'RGC' archetypes, respectively. These predictions are obtained from the $1^{\text {st }}$ stage probit (logit) regressions, associated with the construction of archetypical network-design rationales.

- MERGER is a carrier-specific dummy variable, set equal to '1' (one) in periods after the corresponding airline's consolidation — which would be 2007 for Gol's acquisition of Varig, 2010 for TAM's merger with LAN and 2012 for Azul's acquisition of Trip.

- $P r A r c h \_F S C \times M E R G E R, P r A r c h \_L C C \times M E R G E R$ and PrArch_RGC $\times$ MERGER are interactions of the MERGER variable with the predictions for the latent expected profits, accounting for the impact of these disruptive events on the propensity of a carrier to adhere to (or avoid) a given business model archetype.

- TREND is an increasing discrete linear variable, set to ' 0 ' (zero) at the beginning of the estimation period of the second stage, January 2006. The rationale for using this variable in this stage is that the studied companies could appear to be converging towards each other when, in reality, all of them could be only expanding their networks. This being the case, these companies could not possibly shy away from operating the same markets as their competitors. $^{2}$ 
- $P r A r c h \_F S C \times T R E N D, P r A r c h L C C \times T R E N D$ and $P r A r c h \_R G C \times T R E N D$ are interactions of the TREND variable with the predictions for the latent expected profits, allowing for the investigation of how carriers' behaviors changed over time.

- Regional dummies and seasonality controls, as previously defined in the first stage models, are included here as well.

Below are descriptive statistics of the main variables in the models.

Table A1 - Descriptive statistics of the main variables

\begin{tabular}{lrrrrr}
\hline Variable & Nr. Obs. & Mean & Std. Dev. & Min. & Max. \\
\hline DIST & 40,292 & 0.999 & 0.785 & 0.040 & 3.502 \\
INCOME & 40,292 & 2.438 & 1.263 & 0.335 & 8.098 \\
PAX & 40,292 & 0.370 & 1.227 & 0 & 21.109 \\
HHI & 40,292 & 77.173 & 26.565 & 20.817 & 100 \\
NETWORK (FSC) & 40,292 & 17.080 & 12.617 & 0 & 47 \\
NETWORK (LCC) & 40,292 & 7.412 & 7.994 & 0 & 32 \\
NETWORK (RGC) & 40,292 & 1.540 & 3.824 & 0 & 19 \\
FSC Archetype & 40,292 & 0.397 & 0.489 & 0 & 1 \\
LCC Archetype & 40,292 & 0.244 & 0.430 & 0 & 1 \\
RGC Archetype & 40,292 & 0.046 & 0.209 & 0 & 1 \\
Azul Airlines & 104,307 & 0.314 & 0.464 & 0 & 1 \\
Gol Airlines & 104,307 & 0.496 & 0.500 & 0 & 1 \\
Avianca Airlines & 104,307 & 0.144 & 0.351 & 0 & 1 \\
LATAM Airlines & 104,307 & 0.395 & 0.489 & 0 & 1 \\
MERGER (Trip) & 104,307 & 0.491 & 0.500 & 0 & 1 \\
MERGER (Varig) & 104,307 & 0.912 & 0.283 & 0 & 1 \\
MERGER (LAN) & 104,307 & 0.645 & 0.479 & 0 & 1 \\
\hline
\end{tabular}


${ }^{1}$ Source: National Civil Aviation Agency, Air Transportation Market Statistical Database Monthly Traffic Report, with own calculations.

${ }^{2}$ Notice that this period is not comprised by observations utilized for the construction of the archetypes' rationales. 